\title{
Modeling and Maximum Power Point Tracking Techniques of Photovoltaic Systems
}

\author{
Marcelo Cabral Cavalcanti, ${ }^{1}$ Francisco de Assis dos Santos Neves, ${ }^{1}$ Denizar Cruz Martins, ${ }^{2}$ \\ Emilio José Bueno Peña, ${ }^{3}$ and Euzeli Cipriano dos Santos Júnior ${ }^{4}$ \\ ${ }^{1}$ Departamento de Engenharia Elétrica, Universidade Federal de Pernambuco, 50740-530 Recife, PE, Brazil \\ ${ }^{2}$ Departamento de Engenharia Elétrica e Eletrônica, Universidade Federal de Santa Catarina, 88040-900 Florianópolis, SC, Brazil \\ ${ }^{3}$ Departamento de Electrónica, Universidad de Alcalá, Alcalá de Henares, 28801 Madrid, Spain \\ ${ }^{4}$ School of Electrical and Computer Engineering, Purdue University Indianapolis, Indianapolis, IN 46202, USA
}

Correspondence should be addressed to Marcelo Cabral Cavalcanti; marcelo.cavalcanti@ufpe.br

Received 22 April 2015; Accepted 22 April 2015

Copyright (c) 2015 Marcelo Cabral Cavalcanti et al. This is an open access article distributed under the Creative Commons Attribution License, which permits unrestricted use, distribution, and reproduction in any medium, provided the original work is properly cited.

Many resources nowadays are used for generation of renewable energy. Among these resources solar energy has received more attention in the last years [1]. The market of photovoltaic systems has been increased exponentially, but the government subsidies have been reduced dramatically in recent years. The return on investment mainly relies on selling the energy produced during the photovoltaic plant lifetime. Thus the photovoltaic system must be designed and controlled properly in order to ensure its lifetime and reliability as well as harvest the maximum solar energy [2].

To evaluate the photovoltaic systems, it is important to have algorithms for estimating the electric model parameters of photovoltaic modules. The mathematical description of the characteristic current-voltage is generally represented by a couple of nonlinear equations, which do not present analytical solution. An adequate electric model capable of obtaining the module output characteristic in terms of external conditions such as temperature and irradiance should be chosen for computer simulation [3]. Based on simplified models, the parameters are determined by the algorithms, aiming at the minimization of the error between the curves generated by the model and the curves obtained by experiments.

Different approaches have been implemented to model mathematically the dynamics of the PV modules, but the equivalent circuit representation with single-diode and two-diode models represents the most widely used topologies $[4,5]$. An advantage of using the single-diode model is the possibility of parametrizing it based only on provided information by datasheet.

This special issue contains state-of-the-art papers about maximum power point tracking techniques based on photovoltaic electric model parameters.

In this special issue, the authors focus on the single-diode model due to its simplicity and satisfactory performance. Some authors introduce a novel design of a biaxial solar digital tracking system for photovoltaic power applications, using information and communication technologies to improve the efficiency of the photovoltaic system. Other authors present in a simple approach a maximum power point tracking method based on the measurement of temperature and shortcircuit current. These measurements can precisely define the maximum power point. The temperature is measured with a low cost sensor and the solar irradiance is estimated through the relationship of the measured short-circuit current and its reference. Fast tracking speed and stable steady state are the main advantages of this technique.

There is also a proposal of a maximum power point tracking method with fast dynamic response, simple implementation, and small variation at steady state. The tradeoff between precision and dynamic response is reduced, since the 
maximum power point tracking is performed by the sliding controller and not by the iterative algorithm. The maximum power point tracking is based on a linear approximation which considers the voltage, current, and temperature of the photovoltaic module. A linear approximation is used to establish the sliding surface for the sliding mode. There is another contribution in which the proposed maximum power point tracking scheme is based on algorithm executed in the controller for virtually constructed power-current or power-voltage curve derived from the identified irradiance parameters. Because the algorithm is based on the virtual curve in the controller, the maximum power point search is executed in the controller and can be separated from the converter operation. Therefore, the approach is ultrafast in cases where some prior knowledge about the photovoltaic module characteristics is available.

In this special issue, some authors propose combining variable fractional order incremental conductance algorithm with extensive variable step size control for tracking the maximum power point. Experimental results show the operation of the proposed method by using a $\mathrm{dc} / \mathrm{dc}$ boost converter to adjust the duty cycle. The authors compare the method with the incremental conductance and fractional order incremental conductance methods. There is also a proposal of a reinforcement learning-based maximum power point tracking method for the photovoltaic array. In the method, after observing the environmental conditions of the array, the learning agent determines the perturbation to the operating voltage of the $\mathrm{PV}$ array and receives a reward by the rewarding function. A series of actions with received positive rewards is generated iteratively such that a pair selection strategy is gradually achieved in the "learning" process.

Finally, some authors present an alternative method for dynamic reconfiguration of the connections in a shaded photovoltaic array. The proposed method is characterized by the maintenance of the photovoltaic array size, without removing or adding any module. The use of rough sets theory can lead to a fast and efficient algorithm of reconfiguration.

It is expected that many researchers from academia and industrial area read the papers of this special issue. We hope that readers of this journal find in this special issue important questions that allow researchers to propose improved maximum power point tracking techniques.

Marcelo Cabral Cavalcanti Francisco de Assis dos Santos Neves Denizar Cruz Martins Emilio José Bueno Peña Euzeli Cipriano dos Santos Júnior
[3] A. Chatterjee, A. Keyhani, and D. Kapoor, "Identification of photovoltaic source models," IEEE Transactions on Energy Conversion, vol. 26, no. 3, pp. 883-889, 2011.

[4] S. Liu and R. A. Dougal, "Dynamic multiphysics model for solar array," IEEE Transactions on Energy Conversion, vol. 17, no. 2, pp. 285-294, 2002.

[5] M. G. Villalva, J. R. Gazoli, and E. R. Filho, "Comprehensive approach to modeling and simulation of photovoltaic arrays," IEEE Transactions on Power Electronics, vol. 24, no. 5, pp. 1198$1208,2009$.

\section{References}

[1] M. A. Green, K. Emery, Y. Hishikawa, W. Warta, and E. D. Dunlop, "Solar cell efficiency tables (version 43)," Progress in Photovoltaics: Research and Applications, vol. 22, no. 1, pp. 1-9, 2014.

[2] D. Dondi, A. Bertacchini, D. Brunelli, L. Larcher, and L. Benini, "Modeling and optimization of a solar energy harvester system for self-powered wireless sensor networks," IEEE Transactions on Industrial Electronics, vol. 55, no. 7, pp. 2759-2766, 2008. 

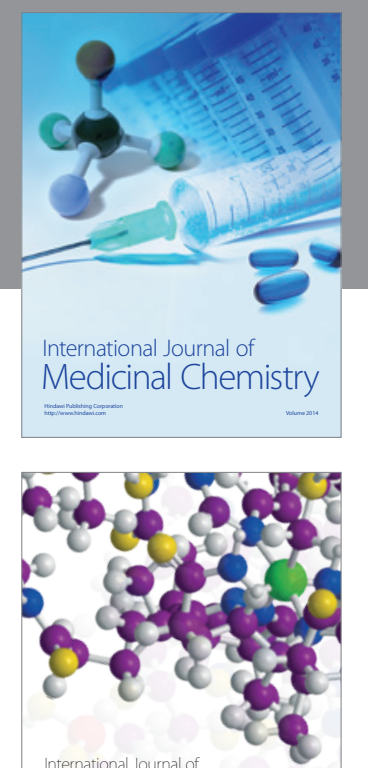

\section{Carbohydrate} Chemistry

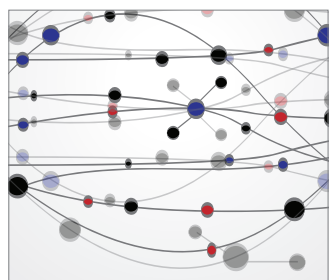

The Scientific World Journal
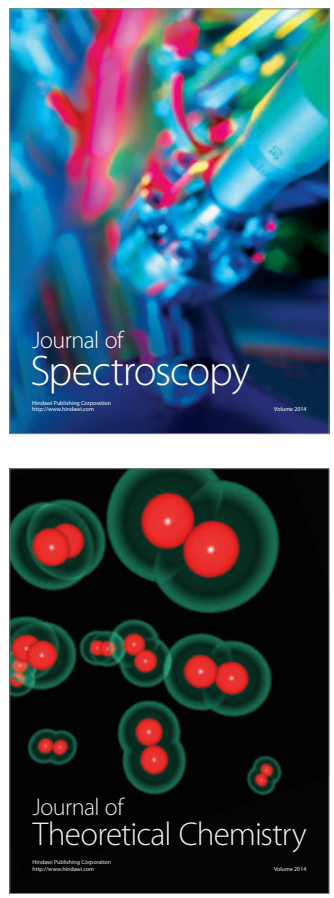
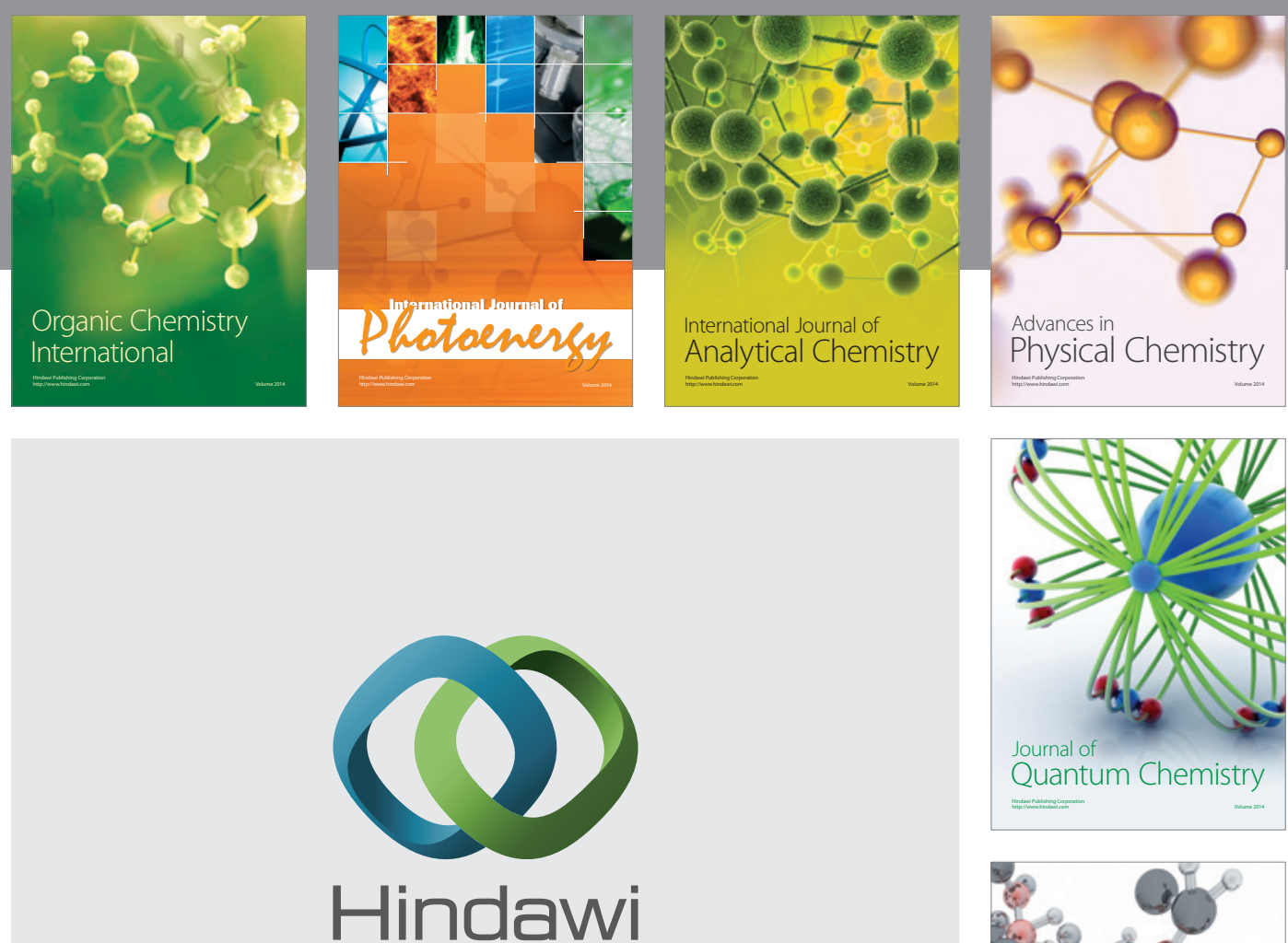

Submit your manuscripts at

http://www.hindawi.com

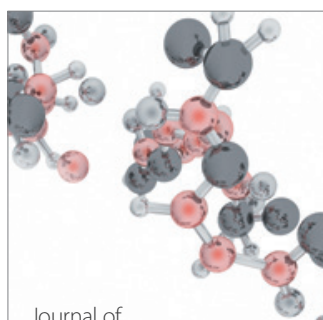

Analytical Methods

in Chemistry

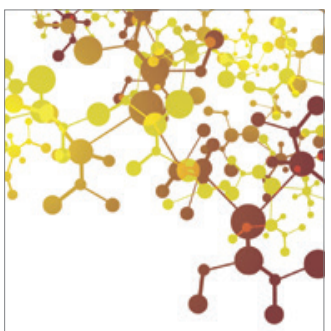

Journal of

Applied Chemistry

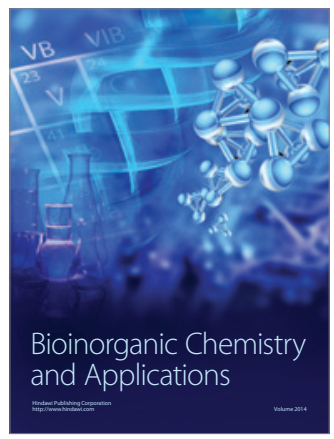

Inorganic Chemistry
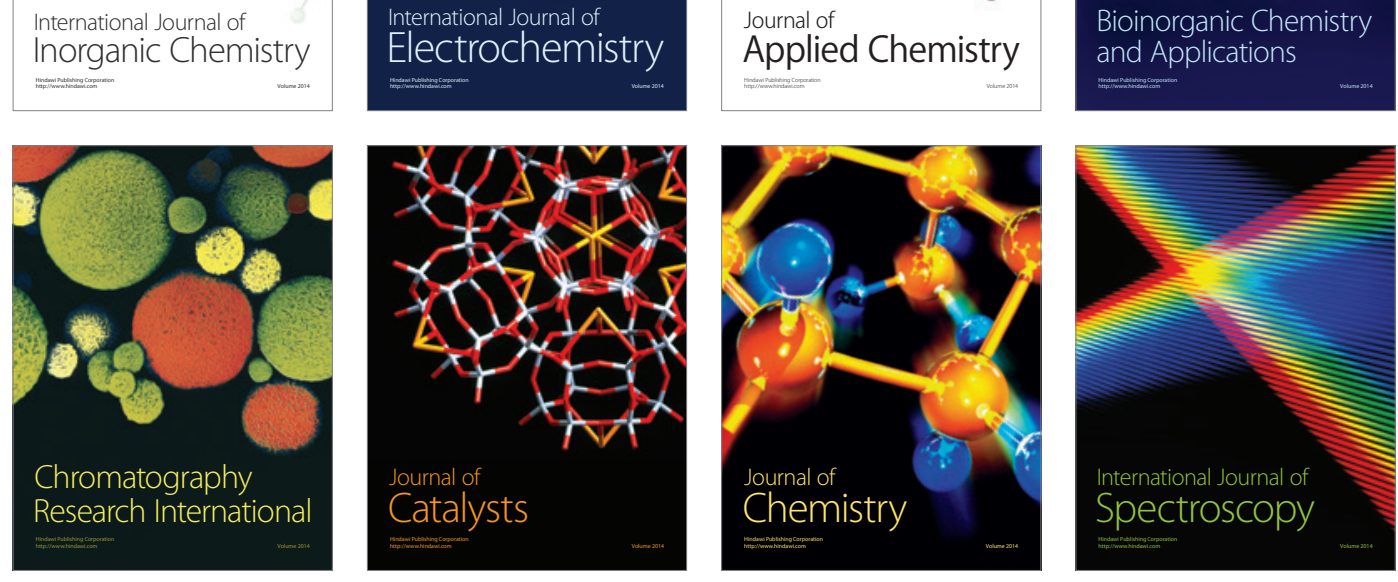